International Journal of Social Science and Economic Research

ISSN: 2455-8834

Volume:05, Issue:09 "September 2020"

\title{
PROSPECT THEORY REVISITED: INVESTIGATING THE APPLICABILITY OF A REVISED VALUE FUNCTION ON DECISIONS THAT BENEFIT THE SELF OR OTHERS
}

\author{
John Leddo and Anchita Shukla
}

MyEdMaster, LLC

John Leddo is the director of research at MyEdMaster, LLC.

DOI: 10.46609/IJSSER.2020.v05i09.018 URL: https://doi.org/10.46609/IJSSER.2020.v05i09.018

\begin{abstract}
Prospect Theory (Kahneman and Tversky, 1979) is a highly influential theory that predicts decision making when people are confronted with choices involving gains or losses with different degrees of uncertainty. Prospect Theory argues that people are generally risk averse when it comes to seeking gains and risk seeking when it comes to seeking losses. Leddo et al. (2019) noted that the original formalization of Prospect Theory did not take into account people's goals. They argued that people would be willing to take risks to achieve goals but become more risk averse once those goals are achieved, and they would become risk averse when confronted with losses in order to avoid a highly negative outcome but become more risk seeking to negate the negative outcome once it occurred. Leddo et al.'s research confirmed this hypothesis, leading to a revision of Prospect Theory's value function. The present research investigates whether the same revised value function can predict recommendations people make on behalf of others in addition to decisions made on behalf of oneself. 80 high school students were presented with scenarios requiring a choice of what standardized test to take to achieve or avoid losing admission to colleges. Gain scenarios depicted students either at or below a score needed to gain acceptance to a dream school. Loss scenarios depicted students either above or at a score that would cause them to lose out on college admission. In half the scenarios, students had to decide which standardized test they would take; in the other half, students had to decide which standardized test to recommend to a friend. Results showed that students made recommendations to their friends that were virtually identical to the decisions they made for themselves. The decisions themselves were consistent with predictions made by Leddo et al.'s (2019) revised value function, namely that high schoolers were more risk seeking when existing test scores were below the requirements of dream colleges than they were when existing scores were at the requirements and that they were more risk averse when existing test scores were in danger of falling to a level that would eliminate chances for getting into college than there were
\end{abstract}




\section{International Journal of Social Science and Economic Research}

ISSN: $2455-8834$

Volume:05, Issue:09 "September 2020"

when scores had fallen to the level that negates chances of getting into college

\section{INTRODUCTION}

One of the most prominent and influential theories of decision making and choice behavior is Kahneman and Tversky's Prospect Theory (1979), which evolved from attempts to understand the place of expectation-based theories in describing individual decision making. Prospect Theory proposes a value function that relates actual outcome value to subjective utility and a decision weighting function which translates the stated probability of an outcome to a subjective weight that the stated probability carries in assessing the attractiveness of that outcome.

The Kahneman and Tversky value function has two distinct properties: a) it is concave for gains and convex for losses so that for example, the difference in utility between 0 and 100 dollars is not the same as the difference in utility between 100 and 200 dollars, and; b) the function for losses is steeper than the function for gains so that a given amount of loss is more aversive than the same amount of gain is attractive. Figure 1 shows Prospect Theory's value function.

Since its inception, there have been many tests of Prospect Theory in a variety of contexts such as business and political decision making (Kahneman \& Tversky, 2000; Jones 2001; Gilovich, Triffen \& Kahneman, 2002; Weyland 2006). Many studies have cited support for some of Prospect Theories main claims. However, results have not always been consistent. For example, Weyland (1996) found that in Latin American countries, politicians facing economic hardships would sometimes enact bold, risky policies and others would enact conservative ones. Similarly, Alghalith et al. (2012) found that investors tended to be risk seeking regardless of whether they were gaining or losing money. Riabacke (2006) examined several lumber companies. These were first grouped into established companies and new and upcoming companies. The companies were asked to choose between a new risky technology not used yet but promised to be more efficient vs the current/old technology. The established company chose the old one while the new company chose the newer technology. Thus, when confronted with the same decision, established companies were risk averse (which generally seems to be the case), whereas the newer companies were risk seeking (which generally seems to be the case). 


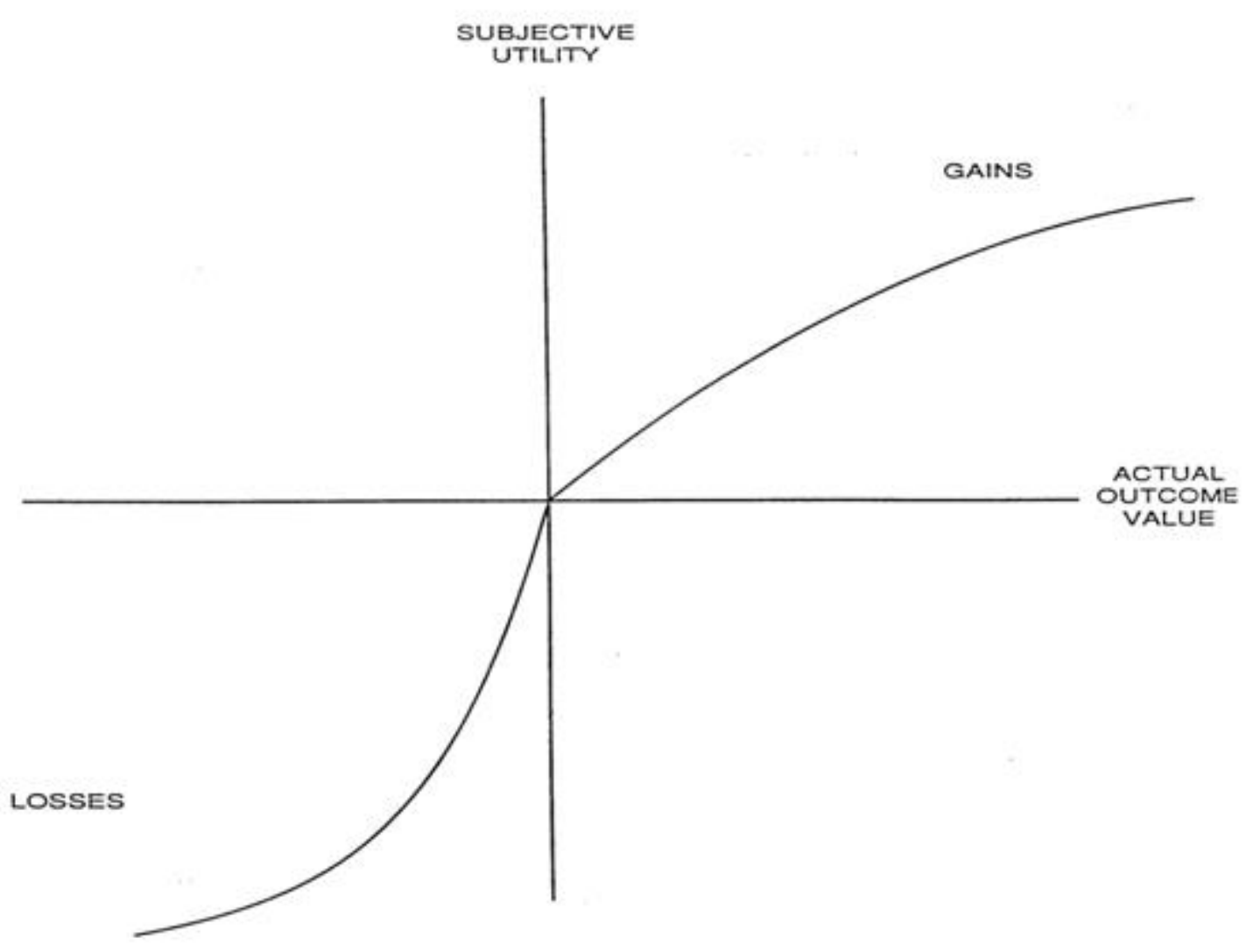

FIGURE 1. Kahneman and Tversky's (1979) value function showing relationship between actual outcome value and subjective utility.

\section{Leddo et al (2019) Extension of Prospect Theory}

Kahneman and Tversky have done an excellent job in explaining cases where people would be risk averse versus risk seeking and have shown how framing choices can lead to one tendency or the other. However, Prospect Theory fails to account for the real-world decisions described above. The reason for this may be reflected in the critique of Prospect Theory offered by Nwogugu (2005) that Prospect Theory was created based on hypothetical decisions that do not reflect the types of real-world decisions involving risk and reward that people typically face. In the real world, gains and losses may not be uniform in how they appear to the decision maker.

As a result, Leddo et al. (2019) noted that real-world decisions often occur in the context of goals, represented in terms of outcomes a decision maker is trying to achieve or ones s/he is trying to avoid. Accordingly, Leddo et al. (2019) created a revised value function that included an aspiration level that represented an outcome the decision maker is trying to achieve and an avoidance level that represented an outcome that the decision maker is trying to avoid. The inclusion of aspiration and avoidance levels in the value function leads to predictions of decision 
making that run counter to those of classical Prospect Theory.

For example, Prospect Theory's value function argues that each successive dollar a person receives is worth less than the previous dollar. However, suppose a person has a goal of becoming a millionaire. While Prospect Theory states that the $10^{\text {th }}$ dollar the person gets along the way towards achieving that goal will be subjectively worth more than the 1 millionth dollar the person gets. Common sense suggests the reverse is true. On the other hand, once the milliondollar goal is achieved, it is reasonable to argue that each successive dollar earned has decreasing subjective value.

Conversely, suppose a person owns a business that will fail if it loses 1 million dollars. Prospect Theory states that each successive dollar lost has decreasing subjective value such that the first dollar lost is subjectively more aversive that losing the one millionth dollar that causes the business to fail. Again, this goes against common sense. As with the argument in the previous paragraph, it is reasonable to also argue that once the one-million-dollar loss occurs and the business is sure to fail, any losses greater than that have decreasing aversiveness.

Accordingly, unlike the traditional Prospect Theory value function, which is concave for gains and convex for losses, the Leddo et al. (2019) revised Prospect Theory value function is convex for gains up to the aspiration level and concave thereafter and concave for losses up to the avoidance level and convex thereafter. The Leddo et al. (2019) revised value function is shown in Figure 2.

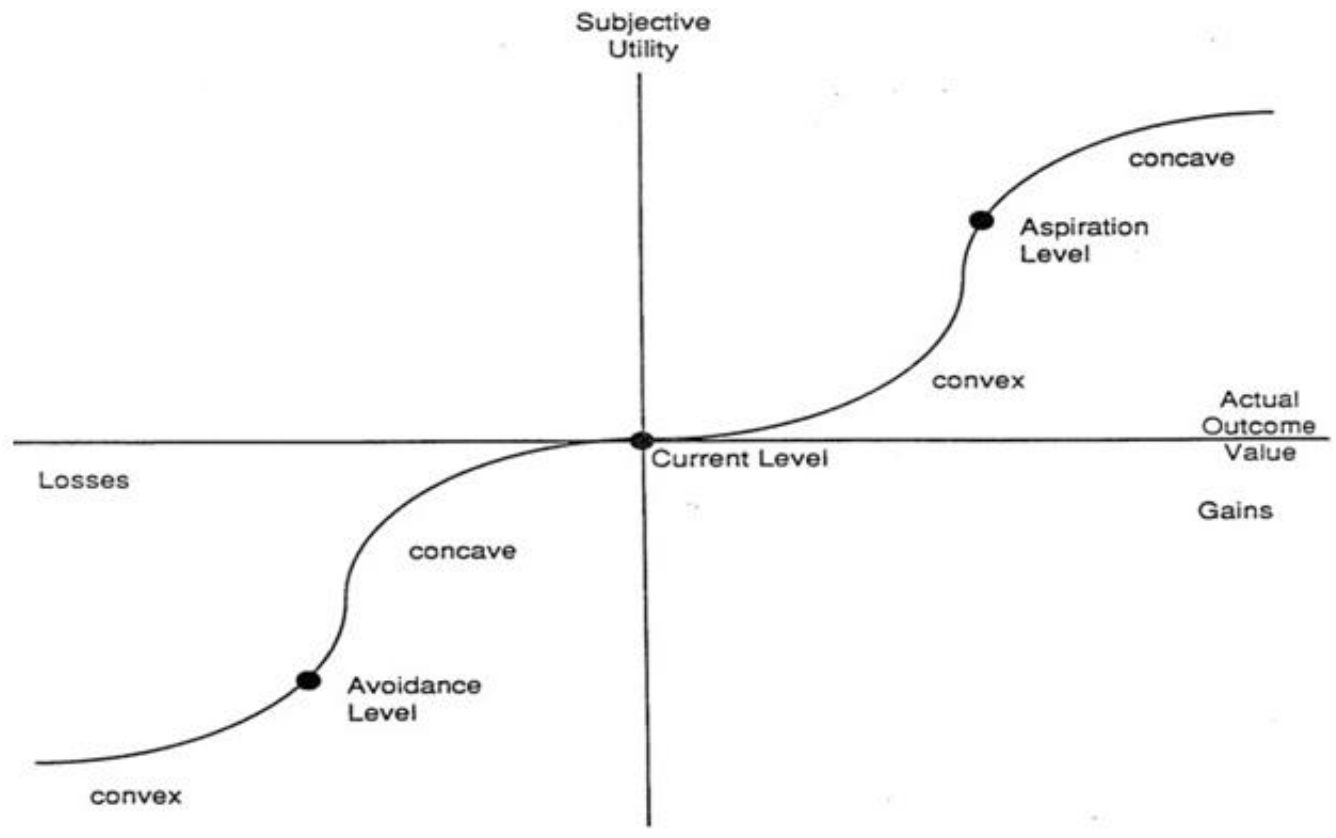




\section{International Journal of Social Science and Economic Research}

ISSN: $2455-8834$

Volume:05, Issue:09 "September 2020"

Figure 2: Revised Prospect Theory value function

The reformulated value function is useful in explaining the empirical results described earlier that appear at odds with the original version of Prospect Theory. For example, investors presumably have a very high aspiration level, so it makes sense for them to be risky when they are gaining money at levels below whatever aspiration level they set. For the lumber companies, new companies have not yet established themselves. Therefore, we would expect new companies to be below their aspiration levels and be willing to engage in risky behaviors. On the other hand, an "established" company has already achieve the goal of becoming successful (its aspiration level), so we would expect to see it to be more risk averse in decision making.

The revised value function is useful in explaining apparent discrepancies in economic policies. For example, when countries show modest economic declines, they often enact austerity programs (e.g., Greece in recent years or the sequester in the United States) that are marked by reduced government spending and attempts to reduce debt. On the other hand, severe economic downturns (e.g., the Great Depression in the 1930's or the recessions in 2008 and 2020 in the United States) are often marked by bold economic initiatives like high government spending, new programs (e.g., the New Deal during the Great Depression), and incurring large amounts of debt. This apparent contradiction can be explained using the avoidance level. As long as the economy has not reached disastrous conditions (the avoidance level), governments are risk averse, but once those levels are reached, they become risk seeking.

While Prospect Theory has been extensively researched, one of the criticisms leveled against this research is that it has focused on decision making for which the decision maker was the primary beneficiary (Nwogugu, 2005). This raises the research question as to whether decision makers would behave differently when evaluating options on behalf of others than when evaluating options on behalf of themselves. Of particular interest to the present research is whether decision makers would act in accordance with the revised Prospect Theory value function as proffered in Leddo et al. (2019).

There is reason to believe, from the existing literature, that people approach decisions for themselves differently than they do for others. Specifically, research suggests that people are more cautious with respect to decisions made for others than decision made for themselves (Beisswanger, et al., 2003; Stone, et al., 2002; Small, 2007; Fernandez-Duque \& Wifall, 2007). This trend held up in a study by Patel and Leddo (2016) in which high schoolers were presented with a scenario in which they or their friends got an unexpected gift of $\$ 1000$ and had to decide how much of that money they or their friends should spend or save. Patel and Leddo (2016) 


\section{International Journal of Social Science and Economic Research}

ISSN: $2455-8834$

Volume:05, Issue:09 "September 2020"

found that high schoolers would spend roughly two-thirds of the $\$ 1000$ received and save one third, while recommending that their friends spend only one-third of the money and save the rest.

The results of these studies suggest that participants may make different decisions themselves than they would recommend for their friends. However, while the Patel and Leddo (2016) study found that high schoolers were more cautious regarding decisions made for themselves vs. those made for friends, the decision involved in that study was made in the absence of goals, just as the decisions made during the original Prospect Theory (1979) research. Therefore, it may be the case that when confronted with decisions where high priority goals are at stake (such as getting into college), people would recommend the same sort of goal seeking behaviors for their friends as they take for themselves (e.g., risk seeking to meet a goal or to overcome a big loss, risk aversion after a goal is achieved or to avoid a critical loss). Accordingly, the present hypothesis is when confronted with decisions involving gains and losses, people will make recommendations for others that are consistent with decisions they make for themselves and that these decisions/recommendations will be consistent with the revised value function presented in Leddo et al. (2019).

\section{Hypotheses to be tested}

Hypothesis 1 is that when confronted with prospect, people will make decisions on behalf of others that are the same as those made on behalf of themselves.

Hypothesis 2 is that decision makers will be more risk seeking in decisions involving potential gains when current outcomes are below the aspiration level than when they at or above the aspiration level. This hypothesis is consistent with and would replicate the findings of Leddo et al. (2019).

Hypothesis 3 is that decision makers will be more risk averse in decisions involving potential losses when current outcomes are below the avoidance level than when they at or above the avoidance level. This hypothesis is consistent with and would replicate the findings of Leddo et al. (2019).

\section{METHOD}

\section{$\underline{\text { Participants }}$}

Particpants were 80 high school students recruited from schools in Northern Virginia. They were not paid for their participation in the study.

Materials Used 


\section{International Journal of Social Science and Economic Research}

ISSN: $2455-8834$

Volume:05, Issue:09 "September 2020"

A total of eight scenarios were used. According to Leddo et al. (2019), there are four distinct portions of the revised Prospect Theory value function. These are: decisions involving gains once a goal or aspiration level has been met; decisions involving gains prior to a goal or aspiration level having been met; decisions involving losses prior to an avoidance level having been met; decision involving losses once an avoidance level has been met. Two versions of a scenario were created for each portion of the Value Function. One version required a person to make a decision regarding himself or herself; the other version required a person to make a recommendation to a friend.

Because the participants were all high school students, scenarios were created that presented goals that were meaningful to such students. The scenarios involved decisions on whether to take an SAT or ACT test that is required for college admission. In each scenario, the student has an existing SAT score. In gain scenarios, the existing SAT score is at or below the level needed to get into a dream college. The student chooses between taking a test that provides a sure gain in test score or one that has a 50-50 chance of no gain or double the sure gain. In loss scenarios, students has a test score above or at a score that would negate his/her ability to get into college. The student chooses between taking a test where there is a sure loss in test score or one that has a 50-50 chance of no loss or double the loss. The actual scenarios presented to students is shown below.

1. Gain-below aspiration level-decision made for self

You currently have a 1400 SAT score. You need 1500 on the SAT or an equivalent ACT score to get accepted to your dream college. Your high school is offering its students an in-school SAT or ACT test and is requiring you to take one of them. This is the last available SAT or ACT test before college applications are due. If you retake the SAT, you will get exactly 50 points more. If you take the ACT, you have a 50\% chance of getting an ACT score equivalent to the 1500 SAT score you need to get accepted and a 50\% chance of getting an ACT score equivalent to your current 1400 SAT score. Will you take the SAT or ACT?

2.Gain-above aspiration level-decision made for self

You currently have a 1400 SAT score. You need 1400 to get accepted to your dream college, so you have made your goal. Your high school is offering its students an in-school SAT or ACT test and is requiring you to take one of them. This is the last available SAT or ACT test before college applications are due. If you retake the SAT, you will get exactly 50 points more. If you take the ACT, you have a 50\% chance of getting an ACT score equivalent to a 1500 SAT score and a 50\% chance of getting an ACT score equivalent to your current 1400 SAT score. Will you take the SAT or ACT? 


\section{International Journal of Social Science and Economic Research}

ISSN: $2455-8834$

Volume:05, Issue:09 "September 2020"

3. Gain-below aspiration level-decision made for friend

Your friend, Jane, currently has a 1400 SAT score. She needs 1500 on the SAT or an equivalent ACT score to get accepted to her dream college. Her high school is offering its students an inschool SAT or ACT test and is requiring her to take one of them. This is the last available SAT or ACT test before college applications are due. If she retakes the SAT, she will get exactly 50 points more. If she takes the ACT, she has a 50\% chance of getting an ACT score equivalent to the 1500 SAT score she needs to get accepted and a $50 \%$ chance of getting an ACT score equivalent to her current 1400 SAT score. Do you advise Jane to take the SAT or ACT?

\section{Gain-above aspiration level-decision made for friend}

Your friend, Jane, currently has a 1400 SAT score. She needs 1400 to get accepted to her dream college, so she has made her goal. Her high school is offering its students an in-school SAT or ACT test and is requiring her to take one of them. This is the last available SAT or ACT test

before college applications are due. If she retakes the SAT, she will get exactly 50 points more. If she takes the ACT, she has a 50\% chance of getting an ACT score equivalent to a 1500 SAT score and a 50\% chance of getting an ACT score equivalent to her current 1400 SAT score. Do you advise Jane to take the SAT or ACT?

\section{Loss-below avoidance level level-decision made for self}

You have an 1100 SAT score. Your high school is offering its students an in-school SAT or ACT and is requiring you to take one of them. This is the last available SAT or ACT test before college applications are due. If you get 1000 on this SAT test or an equivalent score on the ACT test, the colleges you are applying to won't accept you. You are out of practice. If you take the SAT, you are guaranteed to get exactly 50 points lower. If you take the ACT, you have a $50 \%$ chance the equivalent SAT score remains exactly the same and a $50 \%$ chance of getting exactly 100 points lower in terms of equivalent SAT scoring and thus be at the level that the colleges you are applying to won't accept you. Will you take the SAT or ACT?

\section{Loss-below avoidance level level-decision made for friend}

Your friend, Jane, has an 1100 SAT score. Her high school is offering its students an in-school SAT or ACT and is requiring her to take one of them. This is the last available SAT or ACT test before college applications are due. If she gets 1000 on this SAT test or an equivalent score on the ACT test, the colleges she is applying to won't accept her. She is out of practice. If she takes the SAT, she is guaranteed to get exactly 50 points lower. If she takes the ACT, she has a $50 \%$ 
International Journal of Social Science and Economic Research

ISSN: 2455-8834

Volume:05, Issue:09 "September 2020"

chance the equivalent SAT score remains exactly the same and a 50\% chance of getting exactly 100 points lower in terms of equivalent SAT scoring and thus be at the level that the colleges she is applying to won't accept her. Do you advise Jane to take the SAT or ACT?

7. Loss-above avoidance level level-decision made for self

You have a 1000 on the SAT. At this level, the colleges you are applying to won't accept you. Your high school is offering its students an in-school SAT or ACT and is requiring you to take one of them. This is the last available SAT or ACT test before college applications are due. You are out of practice. If you take the SAT, you are guaranteed to get exactly 50 points lower. If you take the ACT, you have a 50\% chance of getting exactly 100 points lower in terms of equivalent SAT scoring or $50 \%$ chance the equivalent SAT score remains exactly the same. Will you take the SAT or ACT?

\section{Loss-above avoidance level level-decision made for friend}

Your friend, Jane, has a 1000 on the SAT. At this level, the colleges she is applying to won't accept her. Her high school is offering its students an in-school SAT or ACT and is requiring her to take one of them. This is the last available SAT or ACT test before college applications are due. She is out of practice. If she takes the SAT, she is guaranteed to get exactly 50 points lower. If she takes the ACT, she has a 50\% chance of getting exactly 100 points lower in terms of equivalent SAT scoring or a $50 \%$ chance the equivalent SAT score remains exactly the same. Do you advise Jane to take the SAT or ACT?

\section{$\underline{\text { Procedure }}$}

All eight scenarios were administered in paper and pencil format. Each participant was given only one scenario so that the participant's decision on the scenario would not be affected by answers given to other scenarios. Therefore, the participant was simply directed to state which of the two tests s/he would take or recommend a friend take, depending upon the requirements of the scenario. Which scenario each participant received as randomly determined.

\section{RESULTS}

In each scenario, participants had to choose between taking an SAT or an ACT exam. In all scenarios, taking the SAT had the guaranteed outcome and ACT had the 50-50 outcome. Therefore, choosing the ACT could be seen as the risky option.

Table 1 presents the number of participants who selected the sure thing outcome (risk averse) and the gamble (risk seeking) for each of the eight scenarios. The "monetary" problems were 
International Journal of Social Science and Economic Research

ISSN: 2455-8834

Volume:05, Issue:09 "September 2020"

those designed to replicate the Kahneman and Tversky findings.

\begin{tabular}{|l|l|l|l|l|}
\hline & $\begin{array}{l}\text { Below-aspiration } \\
\text { level gain }\end{array}$ & $\begin{array}{l}\text { Above-aspiration } \\
\text { level gain }\end{array}$ & $\begin{array}{l}\text { Below-avoidance } \\
\text { level loss }\end{array}$ & $\begin{array}{l}\text { Above-avoidance } \\
\text { level loss }\end{array}$ \\
\hline Self & 90 & 50 & 30 & 90 \\
\hline Friend & 90 & 60 & 50 & 80 \\
\hline
\end{tabular}

Table 1: Percent of participants who selected sure thing outcome when making decisions for self or friends, broken down by type of scenario.

A visual inspection of the table indicates that the choices that people made for themselves were nearly identical to those made for their friends. A chi-square analysis revealed that there was no statistically significant difference between choices made for oneself and choices made for friends. This was true for all four scenario conditions: for pre-aspiration level gains, chi-square $=$ 0 ; for post-aspiration level gains, chi-square $=.20, \mathrm{df}=1, \mathrm{p}=.65$; for pre-avoidance level losses, chi-square $=.83, \mathrm{df}=1, \mathrm{p}=.36$; for post-avoidance level losses, chi-square $=.39, \mathrm{df}=1, \mathrm{p}=.53$.

Because all four major sections of the value function were covered in the present scenarios, the above data offer an opportunity to replicate the findings of Leddo et al. (2019), which found that people were risk seeking for gains below the aspiration level but risk averse for gains above the aspiration level and risk averse for losses below the avoidance level and risk seeking for losses above the avoidance level. Given that there were no statistically significant differences between decisions made for oneself vs. those made for friends, the data for those two groups were combined for purposes of the value function analyses.

As seen in Table 1, 90\% of participants in the below-aspiration level gain scenario chose the risky option compared with 55\% of those in the above-aspiration level gain scenario. This difference is statistically significant, $\mathrm{Z}=2.5, \mathrm{p}<.01$. This result is consistent with the predictions made by the value function presented in Leddo et al. (2019).

Similarly, as seen in Table 1, 85\% of participants in the above-avoidance level loss scenario chose the risky option compared with $40 \%$ of those in the below-avoidance level loss scenario. This difference is also statistically significant, $\mathrm{Z}=3.0, \mathrm{p}<.01$. This result is also consistent with the predictions made by the value function presented in Leddo et al. (2019). 


\section{International Journal of Social Science and Economic Research}

ISSN: $2455-8834$

Volume:05, Issue:09 "September 2020"

\section{DISCUSSION}

There are two major findings in the present study. The first is that the data collected provided further support for Leddo et al.'s (2019) revision of the Prospect Theory value function.

Specifically, in scenarios involving gains, participants were more risk seeking for decisions when current outcomes were below their aspiration level than for decisions where the aspiration level had been attained. Similarly, in scenarios involving losses, participants were more risk averse for decisions when current outcomes were below their avoidance level than for decisions where the avoidance level had been attained. These findings are consistent with the principles behind the Leddo et al. (2019) revision of the Prospect Theory value function. One such principle is that that people are willing to assume risks to achieve goals, but once those goals are attained, people become more cautious to protect those gains. On the other hand, people will be cautious to minimize losses if reaching a certain level of loss has a catastrophic outcome (in this case, losing a college admission), but will assume risks once a catastrophic loss that has occurred.

The second major finding is that when confronted with choices involving risk, the high schoolers who participated in the study made virtually identical recommendations to their friends as they would make choices for themselves. Rather than being more cautious in making recommendations that benefit others than they are in making decisions that benefit themselves, as previous literature suggests, the high schoolers adopted a more goal-oriented approach as described above.

The presence of specific goals seems to be the critical difference in how decision makers made decisions regarding their friends in the Patel and Leddo (2016) study vs. the present one. In Kush and Patel (2016), the scenario presented involved "found money." Given that there were no explicit goals stated on what that money was needed for, high schoolers were more cautious in their recommendations to friends on how to use that money than they were in decisions on their own behalf. On the other hand, in the present study, there were concrete goals the impact to which could be determined for each decision or recommendation made. Accordingly, high schoolers made decisions/recommendations that created the maximum chance that a desired goal would be achieved or a negative outcome would be avoided.

Collectively, the Kush and Leddo (2016) and the present study provide strong support that the Prospect Theory value function as originally stated does not capture decisionmaking behavior in realistic scenarios where goals are involved. The present study extends the Leddo et al. (2019) results to show that the revised value function operates both when people make decision on behalf of themselves or recommendations on behalf of others. Further research could confirm the robustness of the revised value function with respect to other findings of the original Prospect 
International Journal of Social Science and Economic Research

ISSN: 2455-8834

Volume:05, Issue:09 "September 2020"

Theory research such as framing effects.

\section{REFERENCES}

Alghalith, M., Floros, C., \& Dukharan, M. (2012). Testing dominant theories and assumptions in behavioral finance. Proquest.

http://search.proquest.com/docview/1014252017/94778EE9FA05455CPQ/4?accountid=34939

Beisswanger, A. H., Stone, E. R., Hupp, J. M., \& Allgaier, L. (2003). Risk taking in relationships: Differences in deciding for oneself versus for a friend. Basic and Applied Social Psychology, 25, 121-135.

Fernandez-Duque, D., \& Wifall, T. (2007). Actor/observer asymmetry in risky decision making. Judgment and Decision Making, 2, 1-8.

Gilovich, T., Griffin, D., \& Kahneman, D. (Eds.) (2002). Heuristics and Biases: The Psychology of Intuitive Judgment. New York: Cambridge University Press.

Jones, B.D. (2001). Politics and the Architecture of Choice: Bounded Rationality and Governance. London and Chicago: The University of Chicago Press.

Kahneman, D., \& Tversky, A. (1979). Prospect Theory: An Analysis of Decision Under Risk. Econometrica, 47(2), 263-91.

Kahneman, D., \& Tversky, A. (Eds.) (2000). Choices, Values, and Frames. Cambridge: Cambridge University Press.

Leddo, J., Jayanti, A. \& Duan, I. (2019). Prospect Theory Revisited: Incorporating Decision Maker's Goals into the Value Function. International Journal of Social Science and Economic Research, 4(10), 6619-6640.

Nwogugu, M. (2005). Towards multi-factor models of decision making and risk: A critique of Prospect Theory and Related Approaches, part I. The Journal of Risk Finance, 6, 2. pp. 160-162.

Patel, K \& Leddo, J. (2016). "Spend or Save?" Decisions Made by Teens on Behalf of Self or Others. Mediterranean Journal of Social Sciences, 7(4), 274-277.

Riabacke, A. (2006). Managerial Decision Making Under Risk and Uncertainty. IAENG International Journal of Computer Science, Retrieved 
International Journal of Social Science and Economic Research

ISSN: 2455-8834

Volume:05, Issue:09 "September 2020"

from http://www.iaeng.org/IJCS/issues_v32/issue_4/IJCS_32_4_12.pdf

Small, D. A., Loewenstein, G., \& Slovic, P. (2007). Sympathy and callousness: Affect and deliberations in donation decisions. Organizational Behavior and Human Decision Processes, 102, 143-153.

Stone, E. R., Yates, A. J., \& Caruthers, A. S. (2002). Risk taking in decision making for others versus the self. Journal of Applied Social Psychology, 32, 1797-1824.

Weyland, K. (1996). Risk Taking in Latin American Economic Restructuring: Lessons from Prospect Theory. International Studies Quarterly, 40(2), 185-207.

Weyland, K. (2006). Bounded Rationality and Policy Diffusion: Social Sector Reform in Latin America. Princeton and Oxford: Princeton University Press. 